\title{
Menstrual and Reproductive Factors and Risk of Pancreatic Cancer in Women
}

\author{
Sahar Masoudi ${ }^{1}$, Zahra Momayez Sanat ${ }^{2}$, Altun Mahmud Saleh ${ }^{3}$, Neda Nozari ${ }^{4}$, \\ Neda Ghamarzad ${ }^{1}$, Akram Pourshams ${ }^{1,2, *}$
}

1. Digestive Oncology Research Center, Digestive Disease Research Institute, Tehran University of Medical Sciences, Tehran, Iran.

2. Liver and Pancreatobiliary Diseases Research Center, Digestive Diseases Research Institute, Tehran University of Medical Sciences, Tehran, Iran.

3. College of Medicine, Hawler Medical University, Erbil, Iraq.

4. Yas Hospital, Tehran University of Medical Sciences, Tehran, Iran.

\section{* Corresponding Author:}

Akram Pourshams, M.D, M.P.H Digestive Oncology Research Center, Digestive Disease Research Institute, Tehran University of Medical Sciences, Shariati Hospital, North Kargar Ave , P.O.BOX 1411713135, Tehran, Iran Tel: +982182415140 Fax: +982182415400 Email: akrampourshams@gmail.com

Received: 10 Apr. 2017 Accepted: 20 Jun. 2017

\section{ABSTRACT}

\section{BACKGROUND}

Pancreatic cancer $(\mathrm{PC})$ is a deadly disease with a 5-year survival of less than 5\%. Worldwide $\mathrm{PC}$ incidence rates are lower among women than men. While this suggests a protective role for steroid hormones in PC risk, results from epidemiological studies are not consistent.

\section{METHODS}

153 new incident PC cases and 202 controls were recruited from a prospective case-control study, running in a referral center for endoscopic ultrasonography during 2011-2017. A structured valid and reliable questionnaire was used for data collection by a few trained interviewers. Odds ratios and $95 \%$ confidence intervals for reproductive factors and PC were estimated using logistic regression methods.

\section{RESULTS}

Mean age (SD) of the cases and the controls were 63.18 (11.4) and 63.37 (12.0) years, respectively. Age at menarche, age at menopause, number of parity, gravidity, and abortion were not associated with PC risk.

\section{CONCLUSION}

This study does not support the hypothesis that menstrual and reproductive factors are associated with PC risk.

\section{KEYWORDS:}

Pancreas cancer, Women, Reproductive History

Please cite this paper as:

Masoudi S, Momayez Sanat Z, Mahmud Saleh A, Nozari N, Ghamarzad N, Pourshams A. Menstrual and Reproductive Factors and Risk of Pancreatic Cancer in Women. Middle East J Dig Dis 2017;9:146-149. DOI: 10.15171/mejdd.2017.65.

\section{INTRODUCTION}

Exocrine pancreatic cancer (PC) is the 12th most common cancer in the world with 338,000 new cases diagnosed in 2012. ${ }^{1}$ The incidence of PC is approximately $30 \%$ to $50 \%$ higher in men than in women. ${ }^{1} \mathrm{PC}$ has the highest mortality to incidence ratio among all cancers, with a 5-year survival rate of less than $5 \%{ }^{1}$ Although about $35 \%$ of cases could be attributed to tobacco, obesity, heavy alcohol drinking, diabetes, and chronic pancreatitis ${ }^{2,3}$, the etiology of this deadly cancer is largely unknown. Several epidemiological studies have suggested an inverse association between female reproductive factors and the risk of PC but the findings are not conclusive. ${ }^{4,5}$ Estrogen and progesterone receptors both have been found in normal and cancerous pancreatic tissue inconsistently ${ }^{6,7}$ and the role of androgen is not recognized very well. ${ }^{8}$ Thus, we tested the 
Table 1: Comparison of the cases and controls for age, diabetes-related conditions, body mass index, and cigarette smoking

\begin{tabular}{|c|c|c|c|c|c|}
\hline \multirow{2}{*}{ Characteristics } & & Case & Control & $P$-value & \multirow{2}{*}{ OR (CI 95\%) } \\
\hline & & $\mathrm{N}=153$ & $\mathrm{~N}=202$ & $P$ & \\
\hline Age at diagnosis $($ Mean \pm SD & & $63.18 \pm 11.44$ & $63.37 \pm 12.08$ & 0.885 & $0.99(0.98-1.01)$ \\
\hline \multirow[t]{3}{*}{ Body mass index (N [\%]) } & Normal & $37(24.18 \%)$ & $81(40.10 \%)$ & & 1.00 \\
\hline & Overweight & $38(24.83 \%)$ & $76(37.62 \%)$ & & $1.09(0.63-1.89)$ \\
\hline & Obese & $78(50.99 \%)$ & $45(22.28 \%)$ & $<0.001$ & $3.79(2.22-6.47)$ \\
\hline \multirow[t]{2}{*}{ Diabetes (N [\%]) } & No & $114(74.51 \%)$ & $168(83.17 \%)$ & & 1.00 \\
\hline & Yes, diagnosed $2+$ years ago & $39(25.49 \%)$ & $34(16.83 \%)$ & 0.046 & $2.04(1.25-3.32)$ \\
\hline \multirow[t]{2}{*}{ Cigarette smoking (N [\%]) } & Never & $143(93.46 \%)$ & $184(91.9 \%)$ & & 1.00 \\
\hline & Ever & $10(6.54 \%)$ & $18(8.91 \%)$ & 0.883 & $1.06(0.45-2.46)$ \\
\hline \multirow[t]{2}{*}{ Opium (N [\%]) } & Never & $152(99.35 \%)$ & $198(98.02 \%)$ & & 1.00 \\
\hline & Ever & $1(0.65 \%)$ & $4(1.98 \%)$ & $-*$ & $-*$ \\
\hline \multirow[t]{2}{*}{ Alcohol (N [\%]) } & No & $152(99.35 \%)$ & $202(100 \%)$ & & 1.00 \\
\hline & Yes & $1(0.65 \%)$ & $0(0.00 \%)$ & -* & -* \\
\hline
\end{tabular}

* Not calculable

association between menstrual and reproductive factors and PC by conducting a case-control study.

\section{MATERIALS AND METHODS}

This case-control study was approved by the Institutional Review Board of Digestive Disease Research Center, Tehran University of Medical Sciences (IRB number: IRB00001641, Federal wide Assurance number: FWA00015916). The methods of cases and controls recruitment were extensively explained before and are briefly described here. ${ }^{9}$ Cases (those with pathology proven pancreatic adenocarcinoma) and controls (those with normal pancreas and no other cancer) were selected from the patients who referred for endoscopic ultrasonography (EUS) to a university affiliated hospital (Shariati Hospital) in Tehran, Iran, from January 2011 to January 2017. A structured valid and reliable questionnaire was used for data collection by a few trained interviewers. ${ }^{10}$ Weight and height were measured and body mass index (BMI) was calculated, using the weight before involuntary weight loss. BMI was categorized according to the WHO classification to: underweight $(\mathrm{BMI}<18.5)$, normal (BMI: 18.5 - 24.9), overweight (BMI: 25 - 29.9), and obese (BMI over 30). ${ }^{11}$

The American Joint Committee on Cancer (AJCC) TNM staging system was used for PC staging by EUS and other imaging that the patients already had. ${ }^{12}$
Data are expressed as mean \pm SD or frequency and percentage, as appropriate. Differences in frequencies between the cases and controls were evaluated by simple contingency table analysis (Fisher exact test probability test and $\chi^{2}$ test) using the STATA software, version 12.0 (Stata Corp, College Station, TX, USA). Unconditional logistic regression models were computed to test associations between cancer status and reproductive factors. Contingency tables were constructed yielding $\chi^{2} \mathrm{P}$ values, Fisher exact $\mathrm{P}$ values, crude odds ratio (OR), and $95 \%$ confidence interval $(95 \% \mathrm{CI})$. Multiple logistic regression models were analyzed with cancer status as the dependent variable and other variables as the covariates to test for confounding and effect modification.

\section{RESULTS}

153 new incident PC cases and 202 controls were recruited in the study. Mean age (SD) of cases and controls were 63.18 (11.4) and 63.37 (12.0) years respectively. Table 1 compares the potential risk factors of pancreatic cancer for cases and controls.

Only one of the cases had ever used opium and alcohol. So we did not include these risk factors of PC in our analysis. Overall, 10 cases (6.54\%) compared with 18 controls $(8.9 \%)$ had ever smoked cigarette, resulting in an OR: 1.06 (95\% CI; 0.45 - 2.46).

78 cases $(50.99 \%)$ and $45(22.28 \%)$ controls had 
Table 2: Comparison of the Cases and controls for reproductive factors (adjusted for smoking status, body mass index, and diabetes)

\begin{tabular}{|c|c|c|c|c|c|c|}
\hline \multirow{2}{*}{\multicolumn{2}{|c|}{ Reproductive Characteristics }} & \multicolumn{3}{|c|}{ Control } & \multirow{2}{*}{$\begin{array}{l}\text { Crude-OR } \\
\text { (CI 95\%) }\end{array}$} & \multirow{2}{*}{$\begin{array}{c}\text { Adj-OR } \\
\text { (CI 95\%) }\end{array}$} \\
\hline & & $\mathrm{N}=153$ & $\mathrm{~N}=202$ & $P$ & & \\
\hline Gravidity (Mean $\pm \mathrm{SD}$ ) & & $6.33 \pm 3.48$ & $6.35 \pm 3.36$ & 0.919 & $0.99(0.93-1.05)$ & $0.91(0.64-1.30)$ \\
\hline Live birth $($ Mean \pm SD) & & $5.47 \pm 2.97$ & $5.47 \pm 2.86$ & 0.998 & $1.00(0.93-1.07)$ & $1.09(0.76-1.58)$ \\
\hline Age at menarche $($ Mean \pm SD $)$ & & $13.32 \pm 1.27$ & $13.23 \pm 1.21$ & 0.509 & $1.05(0.89-1.25)$ & $1.05(0.88-1.26)$ \\
\hline Age at menopause (Mean $\pm \mathrm{SD})$ & & $57.43 \pm 19.23$ & $55.23 \pm 16.36$ & 0.231 & $1.00(0.99-1.01)$ & $1.00(0.99-1.01)$ \\
\hline \multirow[t]{3}{*}{ Abortion (N [\%]) } & 0 & $80(52.29 \%)$ & $101(50.00 \%)$ & & 1.00 & 1.00 \\
\hline & 1 & $36(23.53 \%)$ & $55(27.23 \%)$ & 0.810 & $0.84(0.51-1.41)$ & $0.91(0.48-1.73)$ \\
\hline & $2+$ & $37(24.18 \%)$ & $46(22.77 \%)$ & & $0.98(0.58-1.67)$ & $1.14(0.37-3.50)$ \\
\hline \multirow[t]{2}{*}{ Sterility history (N [\%]) } & No & $149(97.38 \%)$ & $194(96.04 \%)$ & & 1.00 & 1.00 \\
\hline & Yes & $4(2.61 \%)$ & $8(3.96 \%)$ & 0.568 & $1.53(0.45-5.19)$ & $1.76(0.48-6.45)$ \\
\hline \multirow[t]{2}{*}{ OCP* use (N [\%]) } & No & $119(77.78 \%)$ & $156(77.20 \%)$ & & 1.00 & 1.00 \\
\hline & Yes & $34(22.22 \%)$ & $46(22.80 \%)$ & 0.902 & $0.97(0.58-1.61)$ & $1.07(0.62-1.84)$ \\
\hline
\end{tabular}

*oral contraceptive pill

Table 3: Tumor characteristics of women who developed incident pancreatic cancer

\begin{tabular}{llc}
\hline \multirow{2}{*}{ Tumor characteristics } & & Case \\
\cline { 2 - 3 } & & $\mathrm{N}=153$ \\
\hline Location $(\mathrm{N}[\%])$ & Head & $113(74.83 \%)$ \\
\cline { 2 - 3 } & Body & $33(22.52 \%)$ \\
\cline { 2 - 3 } & Tail & $4(2.65 \%)$ \\
\hline Size $($ Mean \pm SD) & - & $33.93 \pm 0.93$ \\
\hline Stage $(\mathrm{N}[\%])$ & 0 & $2(1.32 \%)$ \\
\cline { 2 - 3 } & I & $16(10.60 \%)$ \\
\cline { 2 - 3 } & II & $26(54.97 \%)$ \\
\cline { 2 - 3 } & III & $24(17.22 \%)$ \\
\cline { 2 - 3 } & IV & \\
\hline
\end{tabular}

obesity resulting in OR: 3.79 (95\% CI; 2.22 - 6.47). 39 $(25.49 \%)$ cases and $34(16.83 \%)$ controls had two years or longer duration of diabetes, prior to pancreatic cancer diagnosis resulting in OR: 2.04 (95\% CI; 1.25 - 3.32).

Table 2 shows adjusted and unadjusted results for no association between menstrual and reproductive factors and PC.

Table 3 shows that about $75 \%$ of PCs were located in the head of pancreas and most PCs were diagnosed in advance stages.

\section{DISCUSSION}

The risk of developing $\mathrm{PC}$ increases with age. The average age at the time of $\mathrm{PC}$ diagnosis is 70 and most
PCs are diagnosed at advance stage. ${ }^{1}$ Our results are comparable with worldwide data in these regards. ${ }^{1} \mathrm{~A}$ pooled analysis of multiple cohort studies, has shown a higher risk of PC among current smokers compared with never smokers (OR: 1.77, 95\% CI 1.38 - 2.26). The risk is increased significantly with greater intensity, duration, and cumulative smoking dose. ${ }^{13}$ Although smoking is one of the most important risk factors for PC, cigarette smoking was not associated with an increased risk for PC in our population as we showed in our previous study. ${ }^{9}$ The present study supports the notion that having diabetes mellitus (more than two years prior to the diagnosis of PC) and obesity are significantly associated with increased incidence of PC. ${ }^{14,15}$

Female steroid hormones are hypothesized to play a protective role in PC risk. Menstrual and reproductive factors, including age at menarche and menopause and parity, were not associated with PC risk in The California Teachers cohort study. ${ }^{4}$ Combined data from two Italian case-control studies ( 285 cases and 713 controls) showed an OR: $0.46(95 \% \mathrm{CI}=0.26-0.85)$ for women with four or more births compared with nulliparous. But other factors, including age at menarche and menopause, and abortion were not associated with PC risk. ${ }^{5}$ In a cohort of Norwegian women (449 PC cases), age at menopause showed a mild positive association with the risk of PC, but parity did not have such an associations. ${ }^{16}$ A metaanalysis in 2013 suggested that higher parity was associated with a decreased risk of PC. ${ }^{17} \mathrm{~A}$ recent study on 
data from the Women's Health Initiative (1003 cases of PC) shows that being parous vs. nulliparous is associated with reduced risk ( $\mathrm{HR}=0.84,95 \%$ CI $0.70-1.00)$, and women who had one to four births are at decreased risk compared with nulliparous women, whereas women who have more than five births have no decrease in risk. Other reproductive factors and exogenous hormone use were not associated with PC risk in that study. ${ }^{18}$ Our results suggest that menstrual, reproductive, and hormonal exposures are unlikely to play a role in the risk for PC.

\section{CONFLICT OF INTEREST}

The authors declare no conflict of interest related to this work.

\section{REFERENCES}

1. Ferlay J, Soerjomataram I, Ervik M, Dikshit R, Eser S, Mathers C, et al. Cancer incidence and mortality worldwide: sources, methods and major patterns in GLOBOCAN 2012. Int J Cancer 2015;136:E359-86. doi: 10.1002/ijc.29210.

2. Yeo TP, Lowenfels AB. Demographics and epidemiology of pancreatic cancer. Cancer J 2012;18:477-84. doi: 10.1097/PPO.0b013e3182756803.

3. Klein AP, Lindström S, Mendelsohn JB, Steplowski E, Arslan AA, Bueno-de-Mesquita HB, et al. An absolute risk model to identify individuals at elevated risk for pancreatic cancer in the general population. PLoS One 2013;8:e72311. doi: 10.1371/journal.pone.0072311.

4. Lee E, Horn-Ross PL, Rull RP, Neuhausen SL, AntonCulver H, Ursin G, et al. Reproductive factors, exogenous hormones, and pancreatic cancer risk in the CTS. Am J Epidemiol 2013;178:1403-13. doi: 10.1093/aje/kwt154.

5. Lucenteforte E, Zucchetto A, Bosetti C, Talamini R, Negri E, Serraino D, et al. Reproductive and hormonal factors and pancreatic cancer risk in women. Pancreas 2011;40:460-3. doi: 10.1097/MPA.0b013e31820bf986.

6. Robles-Diaz G, Duarte-Rojo A. Pancreas: a sex steroiddependent tissue. Isr Med Assoc J 2001;3:364-8.

7. Satake M, Sawai H, Go VLW, Satake K, Reber HA, Hines OJ, et al.Estrogen receptors in pancreatic tumors. Pancreas 2006;33:119-27.

8. Georgiadou D, Sergentanis TN, Sakellariou S, Vlachodimitropoulos D, Psaltopoulou T, Lazaris AC, et al. Prognostic role of sex steroid receptors in pancreatic adenocarcinoma. Pathol Res Pract 2016;212:38-43. doi: 10.1016/j. prp.2015.11.007.

9. Shakeri R, Kamangar F, Mohamadnejad M, Tabrizi R, Zamani F, Mohamadkhani A , et al. Opium use, cigarette smoking, and alcohol consumption in relation to pancreatic cancer. Medicine (Baltimore) 2016;95:e3922. doi: 10.1097/MD.0000000000003922.
10. Farrokhzad S, Nedjat S, Kamangar F, Kamali M, Malekzadeh R, Pourshams A. Validity and reliability of a questionnaire designed to assess risk factors of pancreatic cancer in Iran. Arch Iran Med 2014;17:102-5. doi: 014172/AIM.003.

11. WHO.int. BMI classification. Geneva: World health organization; 2006. [Updated 01/12/2012];Available from: http:// apps.who.int/bmi/index.jsp?introPage = intro_3.html 2011.

12. The American Joint Committee on Cancer (AJCC) TNM staging system available from :https://www.cancer.org/ cancer/pancreatic-cancer/detection-diagnosis-staging/ staging.html.

13. Lynch SM, Vrieling A, Lubin JH, Kraft P, Mendelsohn JB, HartgeP,etal. Cigarette smoking and pancreatic cancer: a pooled analysis from the pancreatic cancer cohort consortium. Am J Epidemiol 2009;170:403-13. doi: 10.1093/aje/kwp134.

14. Pang Y, Kartsonaki C, Guo Y, Bragg F, Yang L, Bian Z, et al. Diabetes, plasma glucose and incidence of pancreatic cancer: A prospective study of 0.5 million Chinese adults and a meta-analysis of 22 cohort studies. Int $J$ Cancer 2017;140:1781-88. doi: 10.1002/ijc.30599.

15. Michaud DS. Obesity and Pancreatic Cancer. Recent Results Cancer Res 2016;208:95-10.

16. Heuch I, Jacobsen BK, Albrektsen G, Kvåle G. Reproductive factors and pancreatic cancer risk: a Norwegian cohort study. Br J Cancer 2008;98:189-93.

17. Zhu B, Zou L, Han J, Chen W, Shen N, Zhong R, et al. Parity and pancreatic cancer risk: evidence from a meta-analysis of twenty epidemiologic studies. Sci Rep 2014;4:5313. doi: 10.1038/srep05313.

18. Kabat GC, Kamensky V, Rohan TE.Reproductive factors, exogenous hormone use, and risk of pancreatic cancer in postmenopausal women. Cancer Epidemiol 2017;49:1-7. doi: 10.1016/j.canep.2017.05.002. 